\title{
COMMUNICATING ACROSS CULTURES AND LANGUAGES IN THE HEALTH CARE SETTING. CLAIRE PENN \& JENNIFER WATERMEYER. PALGRAVE MACMILLAN, UK. 368 PP. ISBN 978-1-137-58100-6
}

\author{
А.А. Харьковская \\ aax2009@mail.ru \\ А.А. Голубых \\ ana.golubykh@ya.ru \\ Самарский национальный исследовательский университет им. С.П. Королева \\ (Самара, Россия)
}

\begin{abstract}
Аннотация: Пандемия сопровождается активным внедрением в мировую коммуникативную практику научно-исследовательских проектов, ориентированных на обмен опытом и совершенствование механизмов профессионального общения в самых различных областях социальной жизни и деятельности. Рецензируемая монография, авторами которой являются профессора кафедры патологии речи и аудиологии Университета Витватерсранда (Южная Африка) Клэр Пенн и Дженнифер Уотермейер, посвящена исследованию особенностей коммуникации в мультикультурных и мультилингвальных учреждениях здравоохранения Южной Африки. В фокусе внимания авторов находится коммуникация, которая является своеобразным мостом, объединяющим голоса окружающего мира с голосом медицины, с одной стороны, а с другой, характеризуется противоречивостью и сложностью в культурно и лингвистически разнообразных контекстах африканского здравоохранения. Цель данного исследовательского проекта состоит в подробном анализе языкового и межьязыкового взаимодействия в медицинских учреждениях, в определении роли культурного брокера - посредника между медицинским работником и пациентом в конкретных условиях общения, а также в выявлении действенных способов, посредством которых исследуемые взаимодействия могут быть скорректированы для улучшения коммуникации. Рецензируемая монография является ценным и достоверным источником знаний для работников здравоохранения, специалистов в области лингвистики и анализа дискурса, преподавателей, обучающих студентов медицинским профессиям и специальностям, практикующих врачей, а также предназначена для исследователей, интересующихся мировым влиянием коммуникативных исследований на профессиональную медицинскую практику.

Ключевые слова: коммуникация, профессиональный медицинский дискурс, мультикультурная и мультилингвальная коммуникация, культурный брокер, учреждения здравоохранения.
\end{abstract}


Для цитирования: Харьковская А.А., Голубых А.А. (2021). Communicating Across Cultures and Languages in the Health Care Setting. Claire Penn \& Jennifer Watermeyer. Palgrave Macmillan, UK. 368 Pp. ISBN 978-1-137-58100-6. Дискурс профессиональной коммуникаичии. 3(4), C. 91-98. https://doi.org/10.24833/2687-0126-2021-3-4-91-98

$P$ ецензируемая монография Communicating Across Cultures and Languages in the Health Care Setting (издательство Palgrave Macmillan, 2018) зарубежных авторов К. Пенн и Дж. Уотермейер занимает особое место в современной научной медицинской парадигме в современных условиях глобализации и медикализации социума. В наши дни в связи с повышенным интересом к здоровью человека как важнейшей ценности и интенсивными темпами проведения медицинских исследований, а также по причине возрастающей роли медицинской науки и здравоохранения в жизни современного социума с учетом злободневной проблемы пандемии Covid-19, охватившей весь мир, медицинская тематика приобретает особую актуальность и неоспоримую значимость.

Зарубежные авторы рецензируемой монографии Клэр Пенн и Дженифер Уотермейер представляют Университет Витватерсранда в Южной Африке. Профессор К. Пенн способствовала развитию нового научного направления в Южной Африке - коммуникации в области здравоохранения - и возглавила новую междисциплинарную исследовательскую организацию Health Communication Research Unit, в которой в настоящее время продолжает работу Дженнифер Уотермейер, профессор кафедры патологии речи и аудиологии Университета Витватерсранда. Основной целью авторского проекта и разработок представленной ими организации является исследование уникальных проблем многоязычного и межкультурного общения в аспекте здравоохранения посредством применения методов социальных и гуманитарных наук при изучении коммуникации в учреждениях здравоохранения с целью усовершенствования медицинских теоретических знаний, со-
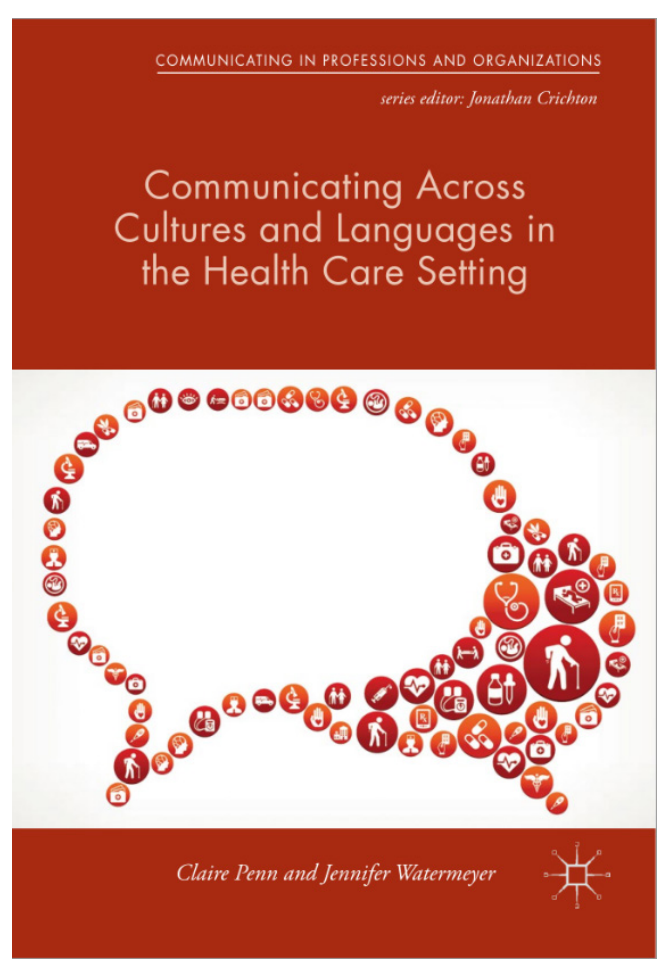
ставления рекомендаций для медицинской политики и практики, а также для разработки и внедрения программ обучения работников здравоохранения коммуникативным навыкам, которые способствуют повышению стремления пациентов к овладению информацией для лечения определенных заболеваний. Развивая исследовательские традиции организации Health Communication Research Unit, К. Пенн и Дж. Уотермейер видят необходимость восполнить пробел между медицинской теорией и практикой [Penn \& Watermeyer, 2018, p. 61], предлагая новый качественный подход к пониманию трудностей общения в культурно и лингвистически разнообразных контекстах здравоохранения, который применяется в более широких международных масштабах с учетом текущих тенденций - глобализации, миграции и медикализации социума, что объективно требует разработки новых действенных методов обучения специалистов здравоохранения профессиональным коммуникативным на- 
выкам и умениям в мультикультурной и мультилингвальной среде. Собственно, именно эти позиции нашли отражение в содержании и названиях частей исследуемой монографии, последовательно и логично представляющей теоретический материал, систему доказательств, основанную на анализе значительного по объему фактического материала и применении и внедрении разработанных методов в медицинской практике:

1. Background and Central Constructs

2. Research Methods and Challenges

3. The Evidence

4. Implementation

Авторы отмечают важнейшую роль общения между медицинским работником и пациентом в терапии тех или иных заболеваний, где коммуникация - это мост, устанавливающий взаимопонимание между ними и помогающий работникам здравоохранения услышать голоса пациентов, и наоборот: "The essence of our research endeavour is to blend the voice of the lifeworld with the voice of medicine and to use communication as that bridge" [Penn \& Watermeyer, 2018, p. 11]. Поскольку настоящее исследование основано на примерах общения с уязвимыми группами населения (люди, которые часто болеют, бедны или не имеют образования), маргинализированными и дискриминированными группами общества, голос которых часто игнорируется, искажается и умалчивается, авторы считают своим этическим долгом представить их мнение посредством используемых качественных методов исследования, сохраняя при этом конфиденциальность. Важно отметить богатство и глубину эмпирического материала, исследуемого в данной работе, фактический материал представлен прямой речью пациента, которая может быть наделена большей силой и красотой, чем ее анализ и интерпретация; при этом особое значение приобретают “јuicy” quotes [Penn \& Watermeyer, 2018, p. 103] - дословные отрывки из интервью, которые наиболее адекватно подкрепляют выводы примерами. В иллюстративном материале монографии прямая речь представлена в нарративах - историях пациентов о своих заболеваниях, а также в интервью и диалогах медицинских работников с пациентами, когда особое внимание уделяется роли культурного брокера (им может быть переводчик или обученная медсестра, хорошо знающие язык и культуру страны пациента), выполняющего функцию медиатора, интерпретирующего общение между работником здравоохранения и пациентом в заданных культурных рамках, что помогает обеим сторонам преодолевать культурные и языковые барьеры для достижения конкретной коммуникативной цели, а именно для корректной постановки диагноза, оптимального выбора подходящей тактики и методики лечения, точного следования врачебным рекомендациям и выполнения схемы лечения.

Следует отметить широкое применение иллюстративного материала в рецензируемой монографии К. Пенн и Дж. Уотермейер, характеризующегося не только эпизодами диалогов, интервью, нарративов, но и многообразием информативных схем разработанных моделей, указывающих на важную роль коммуникации в клинических исследованиях и диагностике, в лечении острых и хронических стадий заболеваний и выборе эффективных методов исследования межкультурной медицинской коммуникации. Обращает на себя внимание также регулярное использование таблиц, рисунков и фотографий, подкрепляющих демонстративную функцию, которая отличается наглядностью представленного материала и способствует точному пониманию авторской концепции.

Рецензируемая монография четко структурирована и отличается логичностью изложения и сбалансированностью теоретического и фактического материала, что позволяет чи- 
тателю составить исчерпывающее представление о структуре и последовательности проведенного исследования.

Первая часть работы Background and Central Constructs дает представление об основных положениях, ключевых концептах, важных темах и проблемах, затрагиваемых в исследовании, а также содержит описание способов их успешного решения. Обсуждается взаимодействие между западными биомедицинскими медико-санитарными структурами по уходу за больными, фокусируется внимание на сильном влиянии гендерных параметров на коммуникацию в контексте здравоохранения, рассматриваются вопросы взаимодействия между болезнью, бедностью и общением, перечисляются причины ограничений, налагаемых на деятельность общественных структур поддержки, описывается взаимодействие голосов разных поколений в медицинском контексте и т.п. В монографии также подчеркивается связь моделей и методов исследования с мировыми трендами медицинского образования и менеджмента.

Вторая часть Research Methods and Challenges посвящена вопросам методологии, в ней анализируется ряд руководящих принципов и методов проведения исследований в области межкультурных учреждений здравоохранения. Базируясь на иллюстративных примерах, авторы описали методы, адаптированные к местным условиям, к рутине и обыденности, обозначив потенциальные трудности. Достоинством рецензируемой монографии К. Пенн и Дж. Уотермейер является использование нескольких методов, что считается отличительной чертой качественной парадигмы научного исследования, а богатство эмпирического материала, полученного в результате применения сочетающихся между собой методов, обеспечивает достоверность полученных результатов. Авторы используют следующие методы и приемы: получение официального доступа в клинику, наблюдение, пространственные и временные аспекты, исследование действием (или экспериментальное исследование), интервью и нарративы, фокус-группы, привлечение культурных брокеров. Важно отметить, что ученые не только перечисляют все используемые ими методы, но и сопровождают их детальной характеристикой, описывая их особенности и предлагая советы по их применению, перечисляя преимущества и предупреждающие аксиомы с учетом их роли в исследовании. Вышеперечисленные параметры используемых методов исследования приведены в таблице, представленной в монографии [Penn \& Watermeyer, 2018, pp. 107-109].

В третьей части The Evidence представлен анализ Islands of Good Practice -геолокаций, в которых были проведены исследования, отметив, что они очевидно демонстрируют качественный уровень общения и заботы в условиях недостаточных ресурсов и потенциальных препятствий (бедность, языковые и культурные различия, временные и пространственные трудности, низкий уровень грамотности) с применением наиболее чувствительных методов, приспособленных к описываемым особенностям. Важной частью данной главы является тщательное исследование языкового разнообразия в клинике, где с помощью продвижения приемов культурного брокерства рассматривается эффективность перевода и стилей интерпретации, предполагающих прямой спонтанный перевод речи пациента (Conduit Style) или фрагментарный перевод отрывков речи пациента и воспроизведение основных моментов (Delayed Style). В ходе изложения стратегий культурного брокерства с акцентом на невербальные и вербальные маркеры, разработанные для устранения коммуникативных сбоев, особое внимание авторов сосредоточено на настоятельной необходимости контроля за темпом языкового взаимодействия между медицинским работником и пациентом в ходе диалога. Кроме того, авторы акцентируют внимание на отступлениях в речи, которые повышают уровень комфорта в общении между переводчиком и пациентом, а также на 
цитировании, которое можно считать особым грамматическим приемом для обозначения сообщаемой речи - в этих случаях по традиции им предшествуют маркеры the doctor is asking или the doctor says; особо авторы останавливаются на приемах переключения с одного языка на другой (code/language switching). К. Пенн и Дж. Уотермейер успешно выявляют вербальные и невербальные аспекты межкультурной коммуникации в учреждениях здравоохранения, которая обычно характеризуется отсутствием помощи со стороны культурных брокеров. Большое внимание уделяется переключению языковых кодов, что помогает приспособиться и ответить потребностям пациента с учетом сложностей понимания и употребления медицинской терминологии в коммуникативной схеме «доктор-пациент». К невербальным аспектам относятся определенные объекты в клинике, жесты, картинки и рисунки, облегчающие взаимодействие между врачом и пациентом. Согласно мнению авторов, неоспоримо важную роль в процессе коммуникации играют “magic” moments [Penn \& Watermeyer, 2018, p. 214] - периоды общения на отвлеченные немедицинские темы, которые отличаются более высоким уровнем взаимопонимания и сотрудничества, а также активным использованием метафор и аналогий, которые смягчают высказывания об определенном заболевании или предоставляют новые способы описания болезней, медицинского обслуживания и связанных с ними переживаний, что может подчеркнуть значимость болезни. Юмор в контексте медицинской коммуникации рассматривается авторами монографии как лекарство, которое может способствовать психологическому исцелению, поскольку призван снимать тревогу как у пациентов, так и у медицинских работников, помогая преодолевать разногласия, облегчая общение на табуированные темы, помогая пациентам справляться со стрессом, вызванным их болезнью, что безусловно обеспечивает успешность взаимопонимания. Однако культурная опосредованность юмора при отсутствии культурной осведомленности участников коммуникации может иметь и негативные последствия. Ученые приходят к обоснованному выводу о том, что вышеперечисленные языковые явления представляют особый интерес в мультикультурной клинике и показывают, что английский язык служит скорее ресурсом и общим языком взаимодействия, чем препятствием в мультикультурном общении, а благодаря совместным усилиям недопонимание некоторых препятствий в общении может быть не столь очевидным даже в отсутствие переводчика.

Четвертая часть Implementation ставит целью внедрение достигнутых результатов исследования и доказательств в повседневную медицинскую практику. Авторы рецензируемой монографии подкрепляют свои доводы примерами и дают ценные советы по применению разработанных ими методов и моделей командного обучения медицинских работников в той или иной медицинской практике. Интересным представляется акроним DRIVE, разработанный для внедрения модели обучения DRIVE model [Penn \& Watermeyer, 2018, p. 282] - с целью помочь участникам запомнить элементы, представляющие особую значимость в процессе взаимодействия между работником здравоохранения и пациентом. Последовательное выполнение действий, предусмотренных этой моделью, обеспечивает успешную мультикультурную и мультилингвальную коммуникацию:

- Discussion of language

- Respect the patient as the expert

- Information must be simplified

- Verify patient understanding of the message

- Ending 
Описания исследовательских проектов, разработанных программ и методов обучения медицинских работников завершаются размышлениями и конструктивными выводами К. Пенн и Дж. Уотермейер по вопросу, который касается результативности разработанных ими проектов и способов их внедрения в медицинские практики, что сопровождается оценкой эффективности программ, методов и проектов: "We have also become aware ... that our methods, materials and findings have a potential for translation into other contexts of linguistic and cultural diversity. Strengthening communication in the clinic appears to reduce asymmetries and strengthen the chain of care" [Penn \& Watermeyer, 2018, p. 308]. В заключении авторы предлагают рекомендации по обучению безопасным в культурном отношении коммуникативным навыкам, необходимым для осуществления успешной коммуникации между медицинским работником и пациентом [Penn \& Watermeyer, 2018, pp. 334-335] и, в очередной раз, подчеркивают, что намеченная ими цель исследования, которая заключается в ориентации на изучение коммуникации в здравоохранении: "our goal may not be communication and health but communication in health - embedded and accepted" [Penn \& Watermeyer, 2018, p. 336], достигнута в границах рецензируемой монографии.

Таким образом, можно сделать вывод, что рецензируемая монография содержит тщательный анализ теоретической литературы, способствующий созданию прочной научно-теоретической базы для последующих практических исследований, выполняемых на серьезной эмпирической базе. Авторская концепция отличается глубиной изложения и обобщения материала, аргументированностью предложенных позиций. Присутствие теоретических, методологических и эмпирических соображений монографии проливает свет на качественные методы исследования и их применение в межкультурном контексте. Эта работа может послужить ценным ресурсом для специалистов в области здравоохранения, педагогов медицинских специальностей, лингвистов, а также ученых, специализирующихся в области дискурсивного анализа и социо-гуманитарных наук.

В заключение хотелось бы поблагодарить авторов Клэр Пенн и Дженифер Уотермейер за качественно подготовленную монографию Communicating Across Cultures and Languages in the Health Care Setting по проблематике межъязыковой и мультикультурной профессиональной медицинской коммуникации, которая несомненно востребована в современном обществе глобализации и медикализации и требует дополнительных усилий работников здравоохранения в процессе их обучения с целью установления успешного коммуникативного взаимодействия с пациентом.

\section{СПИСОК ЛИТЕРАТУРЫ}

1. Penn C., Watermeyer J. Communicating Across Cultures and Languages in the Health Care Setting. Voices of care. Communicating in Professions and Organizations. London: Palgrave Macmillan, 2018. 368 p. DOI: https://doi.org/10.1057/978-1-137-58100-6

\section{REFERENCES}

1. Penn, C., Watermeyer, J. (2018). Communicating Across Cultures and Languages in the Health Care Setting. Voices of care. Communicating in Professions and Organizations. London: Palgrave Macmillan. DOI: https://doi.org/10.1057/978-1-137-58100-6 


\title{
COMMUNICATING ACROSS CULTURES AND LANGUAGES IN THE HEALTH CARE SETTING. CLAIRE PENN \& JENNIFER WATERMEYER. PALGRAVE MACMILLAN, UK. 368 PP. ISBN 978-1-137-58100-6
}

\author{
Antonina A. Kharkovskaya \\ aax2009@mail.ru \\ Anastasia A. Golubykh \\ ana.golubykh@ya.ru \\ Samara National Research University named after Academician S.P. Korolev \\ (Samara, Russia)
}

\begin{abstract}
The book under review presents the challenging and creative research endeavours concerning some peculiar characteristics of multicultural and multilingual communication in South African healthcare settings. The authors of this work - Claire Penn, a professor and director of the Health Communication Research Unit, and Jennifer Watermeyer, an associate professor in the Department of Speech Pathology and Audiology at the University of the Witwatersrand, South Africa, - focus on bridging the gap between the voices of the lifeworld and the voices of medicine via communication characterized by the complexities and pitfalls within culturally and linguistically diverse health care contexts. The research under review is aimed at analyzing the cognitive space of professional medical communication in healthcare settings for applying the results in practice. Research of the cross-language interactions in healthcare facilities (using the evidence from South African medical settings) certainly contributes a lot to establishing an adequate cultural brokers' role in the professional communication and to describing methods aimed at modifying interactions between a healthcare professional and a patient, which taken together lead to the improvement of medical communication in general. This book is a reasonably valuable source of essential knowledge for both healthcare professionals, linguists, discourse analysis researchers, medical educators and practitioners, and for those people who are interested in the specificities of communication research projects in terms of professional medical discourse on the global scale.

Keywords: communication, professional medical discourse, multicultural and multilingual communication, cultural broker, healthcare settings.

How to cite this article: Kharkovskaya A.A., Golubykh A.A. (2021). Communicating Across Cultures and Languages in the Health Care Setting. Claire Penn \& Jennifer Watermeyer. Palgrave Macmillan, UK. 368 Pp. ISBN 978-1-137-58100-6. Professional Discourse \& Communication, 3(4), pp. 91-98. (in Russian). https://doi.org/10.24833/2687-0126-2021-3-4-91-98
\end{abstract}

\section{About the authors:}

Antonina A. Kharkovskaya is Cand. Sci. (Philology), professor in the Department of English philology at Samara National Research University named after Academician S.P. Korolev (Samara, Russia).

Anastasia A. Golubykh is a $\mathrm{PhD}$ researcher in the Department of English philology at Samara National Research University named after Academician S.P. Korolev (Samara, Russia). 